\title{
Interventions to reduce postpartum stress in first-time mothers: a randomized-controlled trial
}

\author{
Hibah Osman ${ }^{*}$, Matilda Saliba², Monique Chaaya ${ }^{3}$ and Georges Naasan ${ }^{4}$
}

\begin{abstract}
Background: The postpartum period can be a challenging time particularly for first-time mothers. This study aimed to assess two different interventions designed to reduce stress in the postpartum among first-time mothers.

Methods: Healthy first-time mothers with healthy newborns were recruited from hospitals in Beirut, Lebanon after delivery. The two interventions were a 20-minute film addressing common stressors in the postpartum period and a 24-hour telephone support hotline. Participants were randomized to one of four study arms to receive either the postpartum support film, the hotline service, both interventions, or a music CD (control). Participants were interviewed at eight to twelve weeks postpartum for assessment of levels of stress as measured by the Cohen Perceived Stress Scale (PSS-10).
\end{abstract}

Results: Of the 632 eligible women, 552 (88\%) agreed to participate in the study. Of those, 452 (82\%) completed the study. Mean PSS-10 scores of mothers who received the film alone (15.76) or the film with the hotline service (15.86) were significantly lower than that of the control group (18.93) ( $p$-value $<0.01$ ). Among mothers who received the hotline service alone mean PSS-10 score (16.98) was also significantly lower than that of the control group ( $p$-value <0.05).

Conclusions: Both our postpartum support film and the 24-hour telephone hotline service reduced stress in the postpartum period in first-time mothers. These simple interventions can be easily implemented and could have an important impact on the mental wellbeing of new mothers.

Trial registration: The trial was registered with clinicaltrials.gov (identifier \# NCT00857051) on March 5, 2009.

Keywords: Postpartum, Stress, Intervention studies, Hotlines, Film

\section{Background}

The postpartum period is a stressful time for women, especially for primiparous mothers [1]. Besides common postpartum stressors like sleep deprivation, hormonal changes, and the demands of caring for a newborn, firsttime mothers have to adapt to their new parenting role [1]. First-time mothers may feel insecure about their abilities to nurture an infant [2]. They often feel overwhelmed, exhausted, and isolated in their new roles [1]. Studies have shown that first-time mothers are at a greater risk of postpartum mental disorders than multiparous mothers [3].

Although postpartum stress has been found to directly correlate with minor postpartum psychiatric illnesses $[4,5]$

\footnotetext{
* Correspondence: h.osman@balsam-lb.org

'Department of Family Medicine, American University of Beirut Medical Center, Beirut, Lebanon

Full list of author information is available at the end of the article
}

including postpartum depression [6-9] and anxiety [10], very few studies have evaluated interventions aiming at reducing postpartum stress. Most preventive postpartum mental health trials targeted depression as their main outcome and most targeted women at risk [11].

In Lebanon, Chaaya and colleagues [12] showed that the prevalence of postpartum depression is approximately $21 \%$. A recent study [13] of perceived stress among postpartum women in Lebanon found that the mean stress score was high when compared to scores in other countries [7].

Interventions that reduce postpartum stress may facilitate the transition into motherhood for first-time mothers.

This study aimed to assess the impact of two simple and flexible interventions on reducing postpartum perceived stress among first-time mothers in Beirut-Lebanon: (1) a postpartum support film and (2) a 24-hour telephone hotline service. These interventions were developed because 
they were simple, cheap, and could be easily reproduced and adapted for implementation in different settings.

\section{Methods}

This study was approved by the American University of Beirut Institutional Review Board in accordance to the National Institute of Health guidelines. The trial was registered with clinicaltrials.gov (identifier \# NCT00857051) on March 5, 2009.

\section{The study participants Eligibility criteria}

It is estimated that $90 \%$ of all deliveries in Lebanon occur in the hospital setting [14]. All first time mothers who were delivering in hospitals in Beirut or its surrounding suburbs were eligible for inclusion in the study. They were excluded if they had any of the following characteristics: (1) had a multiple or complicated gestation, (2) had a chronic disease that required daily management (such as cardiovascular, hypertension, diabetes, or thyroid diseases) and (3) had a baby who required neonatal intensive care. Many women from neighboring countries come to deliver in Beirut and return to their home countries soon after delivery, which would make them inaccessible for a postpartum assessment. We therefore also excluded women who were expected to travel before the assessment would take place.

\section{Study setting}

All hospitals (26 private and one public) in Beirut and close suburbs with maternal services were contacted through a written letter and a meeting with the respective directors to seek their approval for recruiting women. In hospitals where there was an ethics board, applications were submitted for their approval. Twenty-three hospitals agreed to participate; one public (Rafic Hariri University Hospital) and 22 private (American University of Beirut Medical Center, Trad Hospital and Medical Center, Najjar Hospital, Fouad Khoury Hospital, Saint George Hospital Universtiy Medical Center, Makassed Hospital, Bahman Hospital, Sahel General Hospital, Abou Jawdeh Hospital, Al Zahraa University Hospital, Al Rassoul Al Aazam Hospital, Child and Mother Welfare Hospital, Lebanese Canadian Hospital, Saint Therese Hospital, Saint Charles Hospital, Maarbes Hospital, Lebanese Jeitawi Hospital, Beirut General Hospital, Mount Lebanon Hospital, Sacred Heart Hospital, Al Hayat Hospital, and Saint Joseph Hospital).

\section{The study intervention}

Participants were randomized to four arms: postpartum support film, the hotline service, the postpartum support film and the hotline service, or the control group (received a CD of children's music).

\section{Postpartum support film}

The intent of the film is to reduce perceived stress through modifying the cognitive appraisal of postpartum stressors. The literature shows that providing new mothers with a proactive honest reality based approach by changing maternal expectations in the postpartum period would facilitate the transition [15]. Nelson anticipated that telling mothers directly that it is normal to feel overwhelmed, uncertain, and mentally and physically fatigued in the first months postpartum and that assuring them that it is a transient and common experience can help new mothers during the transition $[15,16]$.

The postpartum support film was approximately 20 minutes recorded on a DVD. The film targeted both mothers and fathers and addressed the main stressors in the postpartum period as identified by a previous qualitative study [17]. These included: sleep deprivation, postpartum blues and depression, breastfeeding difficulties, return to work, postpartum sexuality and body changes. The material included presentations by two physicians and testimonials from parents. Although the film included some health related information (e.g. signs that indicate the infant is receiving adequate amounts of breast milk), the main intent was to reassure mothers that the stressors they are experiencing are common and transient. Actors representing first-time mothers were included to provide humor about the stressors.

\section{Hotline service}

The intent of the hotline is to provide immediate reliable answers to concerns that a mother might have. Our hypothesis was that women may be comforted by simply knowing that they had someone reliable to call should they need to regardless of whether they access the hotline or not, and that this would reduce stress. This idea was based on our clinical experience with first-time mothers [17].

The hotline was a telephone number that a mother could call at any time of the day or night to get answers to questions regarding parenting, infant care and self-care issues. The person answering the hotline was a parent or a midwife, trained according to fixed algorithms that were prepared and modified following findings from a previously published pilot hotline study [14]. Algorithms covered topics related to breastfeeding, colic, postpartum blues/ depression, and normal newborn care.

\section{The study outcome}

The main outcome of the study was perceived stress as measured by Cohen Perceived Stress Scale (PSS-10) [18]. PSS-10 has been used to assess perceived stress in a number of different populations including university students, the elderly as well as pregnant and postpartum women [13,19-21]. It was translated into Arabic and validated in Lebanon [13]. 
To evaluate the efficacy of the interventions, the difference of PSS-10 means between each intervention group and the control group was measured at 8-12 weeks postpartum.

\section{Sample size}

The mean score for the PSS-10 was found to be 18.3, with a standard deviation of 4.9 in the validation study among postpartum women in Lebanon [13]. Sample size was calculated based on the aim of reducing the PSS-10 mean by 4 points. Assuming that $50 \%$ of women in the intervention arm would watch the film, the mean for the intervention group was considered to be 16.3. Therefore, 126 women were needed in each arm with an alpha of 0.05 and a power of $90 \%$. A total of 140 women was needed for each arm to allow for $10 \%$ loss to follow up.

\section{Randomization}

We used a randomized controlled single-blinded design. The film, the hotline card, the film and hotline card together, or the music $\mathrm{CD}$ were placed in hard $\mathrm{CD}$ covers which were then placed in sealed opaque envelopes consecutively numbered based on a computer generated random list. All envelopes looked and felt the same. Recruiters were blinded to the content of envelopes. Each participant received the next envelop in the series when she enrolled in the study.

\section{Recruitment}

Baseline data were collected daily over a seven-week period in March and April, 2009 by eight recruiters. Recruiters included midwives and public health graduate students who had been trained for the recruitment process. Recruiters visited their assigned hospitals at the same time every morning. At each hospital visit, the recruiter reviewed the list of deliveries in the last 24 hours and visited every woman who met the inclusion criteria in her room. Written informed consent was obtained from each woman before recruitment. After consenting the woman and providing her with the intervention envelope, a three-minute baseline interview was conducted to gather information about woman's health, the health of her baby, pregnancy and delivery experience, as well as socio-demographic factors.

\section{Follow up assessment}

Data collection in the postpartum period was conducted by 14 trained assessors. Most of the interviews (72\%) were conducted face to face in women's homes; the other $28 \%$ were conducted by telephone due to difficulties in reaching participants in their homes. The postpartum interview lasted between 30 to 50 minutes. In addition to the PSS-10, it included a depression scale, and anxiety scale and questions about general health, mental health, the health of the baby, and social support.

\section{Data analysis}

The data was analyzed using the Statistical Package for the Social Sciences (SPSS) version 16.

Sample characteristics at recruitment and at assessment were presented across each arm. The differences of these characteristics among the four arms were tested using chi-squared test. Significance was considered at $\mathrm{p}$-value $<0.05$. Sample characteristics at baseline included socio-demographic variables such as age, education level, employment and household income. Age was divided into quartiles. Education level was categorized into four groups: 'none/primary', 'middle', 'secondary', and 'university'. Employment was defined as full-time or part-time. Monthly household income was categorized as less than one million, one to two million, and greater than two million Lebanese Pounds (One million Lebanese Pounds $=660$ US dollars). Other indicators included Gravida (Primi/Multi), mode of delivery (Vaginal/C-Section), planned pregnancy (yes/no), and infant gender (female/male).

At follow up, sample characteristics in the postpartum were compared. Maternal variables included mother's health problems (yes/no), breastfeeding (exclusive/mixed/formula only), and smoking (yes/no). A woman was considered a smoker if she had ever smoked in her life due to low frequencies. Infant characteristics included infant health problems (yes/no) and infant's behavior (fussy/non-fussy). Non-fussy infants included easy infants and infants requiring medium effort. Perceived social support in the postpartum was categorized as adequate or inadequate. Marital relationship was divided into satisfactory or not. Life events were assessed by asking women if they had any major events or problems in the last year.

The impact of the interventions was evaluated using intent to treat analyses. The means of PSS-10 were compared between each intervention group and the control group using T-tests. The level of significance was set at $\mathrm{p} \leq 0.05$ for all statistical analyses.

\section{Results}

Of the 751 primiparous women who were approached 119 were excluded and 80 refused to participate (see Figure 1). There were no significant differences in the sociodemographic characteristics of women who participated and those who refused based on the chi-square test at p-value $<0.05$ (Table 1).

Of the 552 participants, 452 were assessed at 8-12 weeks postpartum and 100 were lost to follow up (see Figure 1). There were no significant differences in the sociodemographic characteristics of women who were assessed and those who were lost in follow up (see Table 2).

\section{Participant characteristics}

Table 3 presents the distribution of participants at recruitment according to basic characteristics by intervention 


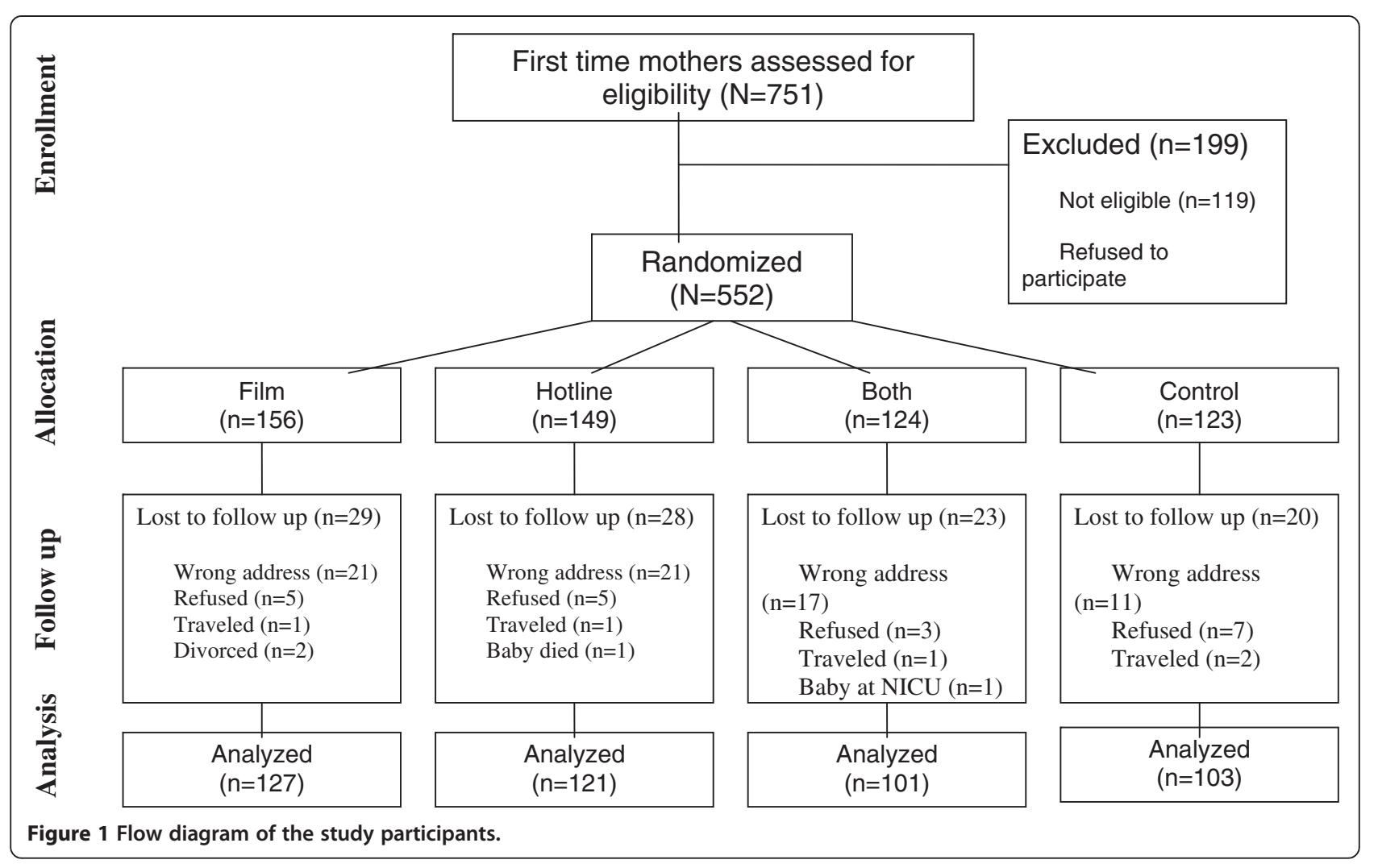

Table 1 Socio-demographic characteristics of women who participated in the study

\begin{tabular}{|c|c|c|c|c|}
\hline & $\begin{array}{l}\text { All } \\
(\mathrm{N}=632)\end{array}$ & $\begin{array}{l}\text { Participated } \\
(\mathrm{N}=552)\end{array}$ & $\begin{array}{l}\text { Refused } \\
(\mathrm{N}=80)\end{array}$ & P-Value \\
\hline Woman's age & & & & 0.34 \\
\hline$<=22$ & 24 & 25 & 17 & \\
\hline $23-25$ & 19 & 18 & 26 & \\
\hline $26-29$ & 28 & 28 & 28 & \\
\hline $30+$ & 29 & 29 & 29 & \\
\hline Woman's education* & & & & 0.27 \\
\hline None/primary & 5 & 5 & 12 & \\
\hline Middle & 26 & 26 & 27 & \\
\hline Secondary & 19 & 19 & 18 & \\
\hline University & 50 & 50 & 42 & \\
\hline Mode of delivery* & & & & 0.29 \\
\hline Vaginal & 54 & 53 & 58 & \\
\hline C-Section & 46 & 47 & 40 & \\
\hline Gravida & & & & 0.18 \\
\hline One & 89 & 88 & 93 & \\
\hline More than one & 11 & 12 & 7 & \\
\hline Baby gender & & & & 0.96 \\
\hline Female & 48 & 48 & 47 & \\
\hline Male & 52 & 52 & 53 & \\
\hline
\end{tabular}

*Columns do not add up due to missing values. arm allocation. Overall, women's age at delivery ranged between 15 and 50 years with a median of 27 years. Most women were educated with $50 \%$ of women having a university degree. More than one third of the women were employed (36.5\%). Forty one percent of first time mothers reported a household income of less than one million Lebanese pounds. Most were primigravida (88.3\%), and nearly two thirds had planned their pregnancy. Cesarean section rate was high - reaching $47 \%$ among the sample. Infant gender was divided almost equally between males $(52 \%)$ and females (48\%). There was no significant difference in the baseline characteristics of participants between the intervention arms.

Table 4 describes main health and social characteristics of first-time mothers in the postpartum period. Few women (18\%) stated that they had a physical problem. Thirty five percent of women were smokers but most stated that they have stopped smoking during pregnancy.

Up to $29 \%$ of the infants had health problems in the first 2-3 months of lives. Only 27\% were exclusively breastfed. Forty percent had breast milk complemented by formula and 33\% were exclusively formula fed. Baby behavior ranged from easy to very fussy. Thirty three percent of mothers reported having a fussy or very fussy baby.

Nearly half the participants (42\%) were not satisfied with their marital relationships and 39\% stated that they had not received adequate social support. Seventeen 
Table 2 Socio-demographic characteristics of women who were lost in follow up as compared to those who were assessed (\%)

\begin{tabular}{|c|c|c|c|}
\hline & $\begin{array}{l}\text { Lost in follow } \\
\text { up }(N=100)\end{array}$ & $\begin{array}{l}\text { Assessed } \\
(\mathrm{N}=452)\end{array}$ & P-Value \\
\hline Woman's age & & & 0.61 \\
\hline$<=22$ & 26.0 & 24.8 & \\
\hline $23-25$ & 22.0 & 17.2 & \\
\hline $26-29$ & 24.0 & 28.8 & \\
\hline $30+$ & 28.0 & 29.2 & \\
\hline Woman's education & & & 0.28 \\
\hline None/primary & 8.1 & 3.8 & \\
\hline Middle & 27.3 & 25.4 & \\
\hline Secondary & 19.2 & 19.6 & \\
\hline University & 45.5 & 51.2 & \\
\hline Woman employment & & & 0.34 \\
\hline Yes & 69.7 & 62.1 & \\
\hline No & 30.3 & 37.9 & \\
\hline Mode of delivery & & & 0.63 \\
\hline Vaginal & 51.0 & 53.7 & \\
\hline C-Section & 49.0 & 46.3 & \\
\hline Gravida & & & 0.43 \\
\hline One & 86.0 & 88.8 & \\
\hline More than one & 14.0 & 11.2 & \\
\hline Baby gender & & & 0.89 \\
\hline Female & 49.0 & 47.8 & \\
\hline Male & 51.0 & 52.2 & \\
\hline
\end{tabular}

*Columns do not add up due to missing values.

percent had experienced a major life event in the last year. None of the variables described above differed significantly across the four arms.

\section{Effect of the intervention on postpartum perceived stress (PSS-10)}

Of the women who received the film as an intervention in arm 1 or 3, 61.8\%reported that they had watched the film. Slightly less than one third (30.2\%) of the women who were randomized to the hotline or hotline and film reported accessing the hotline. Using intent to treat analysis, the Cohen Perceived Stress Scale (PSS-10) mean of each interventional arm was compared with that of the control group (Figure 2). Results of independent T-test showed that the PSS -10 mean \pm SD for first time mothers who received the postpartum support film alone $(15.76 \pm 6.55)$ or the film with the hotline service $(15.86 \pm 6.81)$ was significantly lower than that of the control group $(18.93 \pm 7.03)$ at $p$-value $<0.01$. First time mothers who received the hotline service alone had a PSS-10 mean of $16.98 \pm 6.42$ which was significantly lower than that of the control group at $\mathrm{p}$-value $<0.05$.
Cohen Perceived Stress Scale (PSS-10) means differences between the 3 intervention arms were assessed and found not to be significant.

\section{Discussion}

Both the film and the hotline interventions significantly reduced stress in the postpartum. Participants receiving both interventions had greater reduction in stress levels than either of the interventions alone. This difference, however, was not statistically significant.

The socio-demographic characteristics of the women in the sample were in line with characteristics of women in Beirut. Lebanese women gross enrolment rate for tertiary education is $56.3 \%$ [22] and the employment rate is $21.1 \%$ in Lebanon and $30.8 \%$ in Beirut [23]. The average of monthly household income in Beirut is 909,000 Lebanese pounds [23]. Our finding of a caesarean section rate of $46.8 \%$ approximates the rate published by local insurance companies which is $50 \%$ [14,24].

Both the postpartum support film and the hotline service were effective in reducing early postpartum perceived stress among first-time mothers in Beirut. The impact of the film was stronger than that of the hotline although this difference was not statistically significant.

Few studies have evaluated the effect of interventions on postpartum stress. Other interventions included listening to music [25], home-based physical exercise [26], nurse or community health worker home visits [27], and postnatal support group sessions [28]. The interventions described by Dritsa et al. [26], Chen et al. [28] and Roman et al. [27] were effective in reducing perceived stress [26-28]; however, the first two studies targeted depressed women and the last study targeted women in the low socioeconomic bracket with a late assessment of perceived stress (one year postpartum). Only Tseng at al. [25] targeted women from the general population [25]; however, their intervention did not have a significant effect on postpartum perceived stress. This intervention is therefore the first effective intervention in lowering early postpartum perceived stress among first-time mothers selected from the general population.

This study has several limitations should be considered.

First, the specific aspects of the interventions that affected postpartum stress remain vague. The positive effect of the film could be derived from either the nature of the film, the messages of the film or simply just having something to watch. With regard to the hotline service, simply having access to this service, talking to someone, or having a particular problem addressed by the midwife may have impacted stress levels of the mothers. Second, the interventions reduced postpartum stress at eight to twelve weeks postpartum. Whether such an effect would last beyond that time frame remains unclear. Third, measuring stress at one point in time 
Table 3 Percent distribution of participants by baseline characteristics (at recruitment) and intervention arm

\begin{tabular}{|c|c|c|c|c|c|c|}
\hline & $\begin{array}{l}\text { All arms } \\
(\mathrm{N}=552)\end{array}$ & $\begin{array}{l}\text { Film } \\
(\mathrm{N}=156)\end{array}$ & $\begin{array}{l}\text { Hotline } \\
(\mathrm{N}=149)\end{array}$ & $\begin{array}{l}\text { Both } \\
(\mathrm{N}=124)\end{array}$ & $\begin{array}{l}\text { Control } \\
(\mathrm{N}=123)\end{array}$ & P-Value \\
\hline Age (years) & & & & & & 0.077 \\
\hline$<=22$ & 25.0 & 33.8 & 20.1 & 19.5 & 25.4 & \\
\hline $23-25$ & 18.1 & 16.2 & 16.1 & 20.3 & 20.5 & \\
\hline $26-29$ & 27.9 & 20.1 & 32.9 & 33.3 & 26.2 & \\
\hline $30+$ & 29.9 & 29.9 & 30.9 & 26.8 & 27.9 & \\
\hline Educational level & & & & & & 0.360 \\
\hline None/primary & 4.6 & 7.2 & 3.4 & 2.5 & 4.9 & \\
\hline Middle & 25.7 & 25.5 & 26.5 & 27.0 & 23.8 & \\
\hline Secondary & 19.5 & 16.3 & 23.8 & 14.8 & 23.0 & \\
\hline University & 50.2 & 51.0 & 46.3 & 55.7 & 48.4 & \\
\hline Employed & & & & & & 0.878 \\
\hline Yes & 36.5 & 34.0 & 38.1 & 37.9 & 36.1 & \\
\hline No & 63.5 & 66.0 & 61.9 & 62.1 & 63.9 & \\
\hline Household income (monthly LL)* & & & & & & 0.370 \\
\hline$<1$ million & 41.1 & 41.9 & 39.8 & 38.8 & 43.9 & \\
\hline-2 million & 37.1 & 30.2 & 40.6 & 35.7 & 35.7 & \\
\hline >2million & 21.9 & 27.9 & 19.5 & 20.4 & 20.4 & \\
\hline Gravida & & & & & & 0.180 \\
\hline One & 88.3 & 90.3 & 91.3 & 87.1 & 83.3 & \\
\hline More than one & 11.7 & 9.7 & 8.7 & 12.9 & 16.7 & \\
\hline Planned pregnancy & & & & & & 0.307 \\
\hline Yes & 66.5 & 69.0 & 60.4 & 69.9 & 67.2 & \\
\hline No & 33.5 & 31.0 & 39.6 & 30.1 & 32.8 & \\
\hline Mode of delivery & & & & & & 0.392 \\
\hline Vaginal & 53.2 & 59.1 & 50.7 & 50.8 & 51.2 & \\
\hline C-Section & 46.8 & 40.9 & 49.3 & 49.2 & 48.8 & \\
\hline Baby gender & & & & & & 0.842 \\
\hline Female & 48.0 & 45.5 & 50.3 & 49.2 & 47.2 & \\
\hline Male & 52.0 & 54.5 & 49.7 & 50.8 & 52.8 & \\
\hline
\end{tabular}

${ }^{*}$ Columns do not add up due to missing values.

might have biased the results, as stress may vary from one day to next. Although the questions asked about stress on the Perceived Stress Scale addressed the stress experienced the preceding month, a mother's immediate circumstances could affect her responses. Fourth, although we were able to demonstrate a reduction in perceived stress with both interventions, it remains unclear whether this two to three point reduction on PSS - 10 has any clinical significance. In addition, although recruiters were blinded to the intervention allocation of participants, the assessors could not be blinded since it would have been impossible to insure that participants did not mention that intervention they had received at the time of assessment. At the end of the questionnaire, the assessor asked the participant whether they had watched the film or used the hotline. This might have affected the responses of the Perceived Stressed Scale when it was not self- administered. Given that the study participants were informed at enrolment that the aim of the study was to reduce stress in the postpartum, this may have also biased their responses to the PSS-10 questions as they may have wanted to appear to respond to the intervention to please the assessors. Finally, these interventions had positive impact on new mothers in Beirut, its scope of effectiveness remains vague due to the cultural specificity of the sources of stressors.

\section{Conclusions}

Our interventions are simple and inexpensive and can be replicated and adapted to different settings. They can be delivered through hospitals or health care centers and 
Table 4 Percent Distribution of participants by health and social characteristics at 2-3 months postpartum and intervention arm

\begin{tabular}{|c|c|c|c|c|c|c|}
\hline & $\begin{array}{l}\text { All arms } \\
(\mathrm{N}=452)\end{array}$ & $\begin{array}{l}\text { Video } \\
(N=127)\end{array}$ & $\begin{array}{l}\text { Hotline } \\
(N=121)\end{array}$ & $\begin{array}{l}\text { Both } \\
(\mathrm{N}=101)\end{array}$ & $\begin{array}{l}\text { Control } \\
(N=103)\end{array}$ & P-Value \\
\hline Mother had physical health problem & & & & & & 0.594 \\
\hline Yes & 18.4 & 17.5 & 21.5 & 19.8 & 14.7 & \\
\hline No & 81.6 & 82.5 & 78.5 & 80.2 & 85.3 & \\
\hline Smoking & & & & & & 0.706 \\
\hline Never & 64.8 & 69.1 & 62.8 & 63.6 & 63.1 & \\
\hline Ever & 35.2 & 30.9 & 37.2 & 36.4 & 36.9 & \\
\hline Breast feeding & & & & & & 0.498 \\
\hline Exclusive & 27.4 & 27.6 & 33.9 & 27.7 & 19.4 & \\
\hline With formula milk & 39.6 & 40.2 & 38.0 & 36.6 & 43.7 & \\
\hline Only formula milk & 33.0 & 32.3 & 28.1 & 35.6 & 36.9 & \\
\hline Baby had health problem & & & & & & 0.498 \\
\hline Yes & 28.8 & 26.0 & 33.1 & 30.7 & 25.2 & \\
\hline No & 71.2 & 74.0 & 66.9 & 69.3 & 74.8 & \\
\hline Infant's behavior & & & & & & 0.578 \\
\hline Easy to normal & 67.0 & 67.7 & 66.9 & 71.3 & 62.1 & \\
\hline Fussy & 33.0 & 32.3 & 33.1 & 28.7 & 37.9 & \\
\hline Marital relationship & & & & & & 0.203 \\
\hline Satisfactory & 58.3 & 58.7 & 58.3 & 65.3 & 50.5 & \\
\hline Unsatisfactory & 41.7 & 41.3 & 41.7 & 34.7 & 49.5 & \\
\hline Received social support & & & & & & 0.20 \\
\hline Adequate & 65.9 & 61.1 & 69.7 & 72.0 & 61.4 & \\
\hline Not adequate & 34.1 & 38.9 & 30.3 & 28.0 & 38.6 & \\
\hline Major life event & & & & & & 0.330 \\
\hline Yes & 16.6 & 15.7 & 17.4 & 11.9 & 21.4 & \\
\hline No & 83.4 & 84.3 & 82.6 & 88.1 & 78.6 & \\
\hline
\end{tabular}

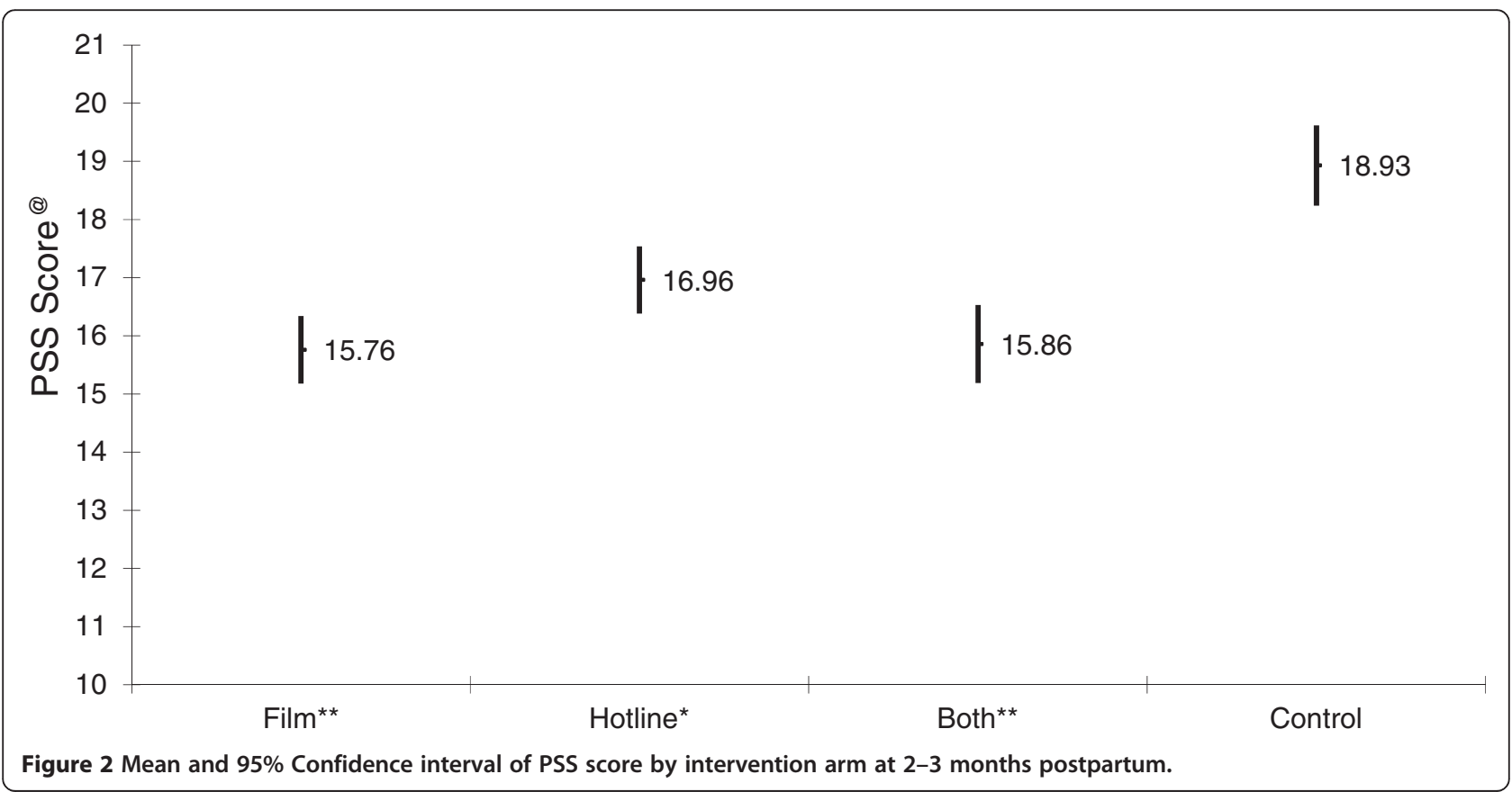


easily integrated into available maternal health services. Future studies should assess the impact of these interventions in different populations. The high prevalence of stress we noted in our studies of the postpartum period is concerning. Studies to understand the implications of stress in the postpartum on other aspects of mental health and the family system would be informative.

\section{Abbreviations}

PP: Postpartum; PSS-10: Cohen perceived stress scale.

\section{Competing interests}

The authors declare that they have no competing interests.

\section{Authors' contributions}

$\mathrm{HO}, \mathrm{MS}, \mathrm{MC}$ and GN contributed to the conceptualization of the study and the study design. MS and MC conducted the data analysis. HO, MS, MC and GN contributed to the writing and read and approved the final manuscript.

\section{Acknowledgements}

The authors would like to thank Nisrine Abi Rizk, Livia Wick, and Lama El Zein for their contributions to this study. We would also like to thank the Choices and Challenges in Changing Childbirth research group at the American University of Beirut and the Reproductive Health Working Group for their feedback and contributions to the study designs. This study was conducted at the Faculty of Health Sciences at the American University of Beirut.

This study was supported by the Center for Research on Population and Health at the American University of Beirut Faculty of Health Sciences through a generous contribution from the Wellcome Trust [Grant \# 074986/Z/04/Z].

\section{Author details}

'Department of Family Medicine, American University of Beirut Medical Center, Beirut, Lebanon. ${ }^{2}$ Research Institute of McGill University Health Center, Montreal, Canada. ${ }^{3}$ Department of Epidemiology and Population Health, American University of Beirut, Beirut, Lebanon. ${ }^{4}$ Memory and Aging Center, Department of Neurology, University of California, San Francisco, USA.

Received: 25 April 2014 Accepted: 29 September 2014

Published: 15 October 2014

\section{References}

1. George L: Lack of preparedness: experiences of first-time mothers. MCN Am J Matern Child Nurs 2005, 30:251-255.

2. Wilkins $C:$ A qualitative study exploring the support needs of first-time mothers on their journey towards intuitive parenting. Midwifery 2006, 22:169-180.

3. Munk-Olsen T, Laursen TM, Pedersen CB, Mors O, Mortensen PB: New parents and mental disorders: a population-based register study. JAMA 2006, 296:2582-2589.

4. Hung CH: Postpartum stress as a predictor of women's minor psychiatric morbidity. Community Ment Health J 2007, 43:1-12.

5. Hung $\mathrm{CH}, \mathrm{Yu} \mathrm{CY}$, Ou CC, Liang WW: Taiwanese maternal health in the postpartum nursing centre. J Clin Nurs 2010, 19:1094-1101.

6. Barnet B, Duggan AK, Wilson MD, Joffe A: Association between postpartum substance use and depressive symptoms, stress, and social support in adolescent mothers. Pediatrics 1995, 96:659-666.

7. Gao LL, Chan SW, Mao Q: Depression, perceived stress, and social support among first-time Chinese mothers and fathers in the postpartum period. Res Nurs Health 2009, 32:50-58.

8. Groer MW, Morgan K: Immune, health and endocrine characteristics of depressed postpartum mothers. Psychoneuroendocrinology 2007, 32:133-139.

9. Hung CH: Predictors of postpartum women's health status. J Nurs Scholarsh 2004, 36:345-351.

10. Wenzel A, Haugen EN, Jackson LC, Robinson K: Prevalence of generalized anxiety at eight weeks postpartum. Arch Womens Ment Health 2003, 6:43-49.

11. Dennis CL, Creedy D: Psychosocial and psychological interventions for preventing postpartum depression. BMJ 2005, 331:15-21.
12. Chaaya M, Campbell OM, El Kak F, Shaar D, Harb H, Kaddour A: Postpartum depression: prevalence and determinants in Lebanon. Arch Womens Ment Health 2002, 5:65-72.

13. Chaaya M, Osman H, Naassan G, Mahfoud Z: Validation of the Arabic version of the Cohen Perceived Stress Scale (PSS-10) among pregnant and postpartum women. BMC Psychiatry 2010, 10:111.

14. Osman H, Chaaya M, El Zein L, Naassan G, Wick L: What do first-time mothers worry about? A study of usage patterns and content of calls made to a postpartum support telephone hotline. BMC Public Health 2010, 10:611.

15. Nelson AM: Transition to motherhood. J Obstet Gynecol Neonatal Nurs 2003, 32:465-477.

16. Saliba M: Promoting Postpartum Maternal Mental Health: An Intervention Study in Beirut, Lebanon [Thesis]. London South Bank University; 2013.

17. Wick L, Osman H: Postpartum stressors in Lebanon; an ethnographic study. 2008, unpublished.

18. Cohen S, Kamarck T, Mermelstein R: A global measure of perceived stress. J Health Soc Behav 1983, 24:385-396.

19. Bastani F, Hidarnia A, Kazemnejad A, Vafaei M, Kashanian M: A randomized controlled trial of the effects of applied relaxation training on reducing anxiety and perceived stress in pregnant women. $J$ Midwifery Womens Health 2005, 50:e36-e40.

20. Wang SY, Chen CH: Psychosocial health of Taiwanese postnatal husbands and wives. J Psychosom Res 2006, 60:303-307.

21. Roberti J, Harrington L, Storch E: Further psychometric support for the 10-Item version of the perceived stress scale. J University Counseling 2006, 9:135-147.

22. The World Bank: The Status and Progress of Women in the Middle East and North Africa. Washington D.C: The World Bank; 2009.

23. The Central Adminstration of Statistics Lebanon: Living Conditions Survey. Beirut: Republic of Lebanon; 2007 (Available at www.cas.gov.lb).

24. Mednet Liban: Cesarean Section. The Global. Qatar: GlobeMed Itd; 2010.

25. Tseng $\mathrm{YF}$, Chen $\mathrm{CH}$, Lee CS: Effects of listening to music on postpartum stress and anxiety levels. J Clin Nurs 2010, 19:1049-1055.

26. Dritsa M, Dupuis G, Lowensteyn I, Da Costa D: Effects of home-based exercise on fatigue in postpartum depressed women: who is more likely to benefit and why? J Psychosom Res 2009, 67:159-163.

27. Roman LA, Gardiner JC, Lindsay JK, Moore JS, Luo Z, Baer LJ, Goddeeris JH, Shoemaker AL, Barton LR, Fitzgerald HE, Paneth N: Alleviating perinatal depressive symptoms and stress: a nurse-community health worker randomized trial. Arch Womens Ment Health 2009, 12:379-391.

28. Chen CH, Tseng YF, Chou FH, Wang SY: Effects of support group intervention in postnatally distressed women. A controlled study in Taiwan. J Psychosom Res 2000, 49:395-399.

doi:10.1186/1472-6874-14-125

Cite this article as: Osman et al:: Interventions to reduce postpartum stress in first-time mothers: a randomized-controlled trial. BMC Women's Health 2014 14:125.

\section{Submit your next manuscript to BioMed Central and take full advantage of:}

- Convenient online submission

- Thorough peer review

- No space constraints or color figure charges

- Immediate publication on acceptance

- Inclusion in PubMed, CAS, Scopus and Google Scholar

- Research which is freely available for redistribution 